\title{
Fabrication and characterization of silk fibroin-derived curcumin nanoparticles for cancer therapy
}

This article was published in the following Dove Press journal:

International Journal of Nanomedicine

II May 2009

Number of times this article has been viewed

Vishal Gupta'

Abraham Aseh ${ }^{1,3}$

Carmen N Ríos'

Bharat B Aggarwal ${ }^{2}$

Anshu B Mathur'

'Department of Plastic Surgery;

${ }^{2}$ Department of Experimental

Therapeutics, The University of Texas

M.D. Anderson Cancer Center,

Houston, TX, USA; ${ }^{3}$ School of

Pharmacy, Texas Southern University,

Houston, TX, USA
Correspondence: Anshu B Mathur Tissue Regeneration and Molecular Cell Engineering Labs (TRAMCEL), Department of Plastic Surgery, The University of Texas M.D. Anderson Cancer Center, 1515 Holcombe Blvd., Unit 602, Houston, TX 77230-1402, USA Tel + I 7135637568

Fax $+|7| 3563023 \mid$

Email amathur@mdanderson.org
Abstract: Biologically derived nanoparticles $(<100 \mathrm{~nm})$ were fabricated for local and sustained therapeutic curcumin delivery to cancer cells. Silk fibroin (SF) and chitosan (CS) polymers were blended noncovalently to encapsulate curcumin in various proportions of SF and CS (75:25, 50:50, and 25:75 SF:CS) or pure SF at two concentrations $(0.1 \% \mathrm{w} / \mathrm{v}$ and $10 \% \mathrm{w} / \mathrm{v})$ using the devised capillary-microdot technique. Curcumin-polymer conjugates were frozen, lyophilized, crystallized, suspended in phosphate-buffered saline for characterization, and tested for efficacy against breast cancer cells. All nanoparticle formulations except $0.1 \% \mathrm{w} / \mathrm{v}$ 50:50 SFCS were less than $100 \mathrm{~nm}$ in size as determined with the transmission electron microscopy. The entrapment and release of curcumin over eight days was highest for SF-derived nanoparticles as compared to all SFCS blends. The uptake and efficacy of SF-coated curcumin was significantly higher $(\mathrm{p}<0.001)$ than SFCS-coated curcumin in both low and high Her2/neu expressing breast cancer cells. Interestingly, the uptake of curcumin was highest for the high Her2/neu expressing breast cancer cells when delivered with a $10 \% \mathrm{w} / \mathrm{v}$ SF coating as compared to other formulations. In conclusion, SF-derived curcumin nanoparticles show higher efficacy against breast cancer cells and have the potential to treat in vivo breast tumors by local, sustained, and long-term therapeutic delivery as a biodegradable system.

Keywords: biodegradable, nanoparticles, curcumin, silk fibroin, breast cancer cells

\section{Introduction}

Drug delivery to tumors is exacerbated by the toxicity to normal tissue in conjunction with low absorption at the tumor-site due to low retention of drugs by the tumor cells. The treatment of solid tumors such as pancreatic cancer, cervical cancer, and breast cancer with chemotherapeutic hydrophobic agents like 'curcumin' is limited by the lack of bioavailability and tissue specificity. ${ }^{1}$ Curcumin is a yellow polyphenol extracted from the rhizome of turmeric, which has strong activity as an anti-cancer agent as it inhibits proliferation of various tumor cells. ${ }^{2}$ Previously, curcumin was shown to suppress many tumorogenic pathways, including the Her2/neu pathway, in breast cancer cells. ${ }^{2,3}$

In order to enhance the bioavailability of curcumin, several approaches have been taken including the development of curcumin nanoparticles. Recent studies demonstrated various formulations of curcumin nanoparticles using polymeric materials, ${ }^{4,5}$ solid lipids, ${ }^{6}$ and liposomes. ${ }^{7-9}$ Although the use of liposomes reduced the toxicity, no tissue specificity is associated with the liposomes. Additionally, none of the above formulations were derived from natural polymers that would eliminate tissue toxicity while simultaneously increasing bioavailability. 
Silk microspheres, ${ }^{10,11}$ nanolayers, ${ }^{12}$ and coatings on drug-loaded liposomes ${ }^{13,14}$ were previously used for the controlled release of various other drugs. Previously, silk fibroin (SF)-coated liposomal emodin was shown to have higher efficacy against breast cancer cells as compared to the uncoated liposomal emodin due to increased retention of emodin in the presence of SF..$^{14}$ Loading the drug into liposomes and then coating them with SF produced particles that were larger in size than $100 \mathrm{~nm} .{ }^{13}$

Therefore, this study was focused on harnessing the properties of the SF polymer as a drug delivery agent in order to increase the retention, efficacy, and bioavailability of curcumin by packaging it as a nanoparticle $(<100 \mathrm{~nm})$. Moreover, SF was blended with chitosan (CS), since this blend was shown to be biocompatible, biodegradable, and supports the in vivo regeneration of tissues. ${ }^{15}$ Both SF and CS are derived from natural biopolymers. In this study, we investigated the fabrication and characterization (size, entrapment efficiency, and in vitro drug release) of SF- and CS-derived curcumin nanoparticles. Also, the intracellular uptake and efficacy of curcumin nanoparticles on low and high Her2/neu-expressing breast cancer cells was analyzed. Although curcumin was shown to suppress many tumorogenic pathways ${ }^{2,3}$ this is the first time that curcumin nanoparticles have shown efficacy towards breast cancer cells.

\section{Materials and methods Preparation of silk fibroin and chitosan blends}

Raw silk (Sao Paulo, Brazil) was generously donated by Dr Sam Hudson (North Carolina State University, Raleigh, NC) and high molecular weight chitosan ( $82.7 \%$ deacetylation) was obtained from Sigma-Aldrich (St. Louis, MO). Processing of SF and preparation of SFCS blends has been described previously. ${ }^{16}$ In brief, raw silk was degummed in $0.25 \%(\mathrm{w} / \mathrm{v})$ sodium carbonate and $0.25 \%(\mathrm{w} / \mathrm{v})$ sodium dodecylsulfate (Sigma-Aldrich) for one hour at $100{ }^{\circ} \mathrm{C}$ and then dissolved in calcium nitrate tetrahydrate and methanol solution (molar ratio of 1:4:2 $\mathrm{Ca}: \mathrm{H}_{2} \mathrm{O}: \mathrm{MeOH}$ ) at $65{ }^{\circ} \mathrm{C}$. Chitosan was dissolved separately in a $2 \%$ acetic acid solution at the same concentration as silk fibroin solution and was mixed together to prepare a particular blend. For example, three parts of SF were mixed with one part of CS to prepare 75:25 SFCS. The SFCS solution was then dialyzed against ultrapure water for four days and filtered. The final solution was $10 \% \mathrm{w} / \mathrm{v}$ of SF or SFCS and diluted 100 times to make $0.1 \% \mathrm{w} / \mathrm{v}$ solutions.

\section{Preparation of nanoparticles}

Curcumin powder was weighed $(1 \mathrm{mg})$ and suspended in $100 \mu 1$ of 25:75, 50:50, or 75:25 SFCS and SF only. These nanoparticles were prepared using the capillary microdot technique. The drug suspension was dispensed on glass slides via a microcapillary. The slides were then frozen overnight and lyophilized. Dry dots containing SFCS-coated curcumin nanoparticles were scraped off the slides and collected in a $1.5 \mathrm{ml}$ centrifuge tube. The SFCS coating was crystallized by suspending nanoparticles in $0.5 \mathrm{ml}$ of 50:50 methanol and $1 \mathrm{~N}$ sodium hydroxide solution (for SF coating, only methanol was used) for 15 minutes. ${ }^{13}$ The suspension was centrifuged at $8,960 \mathrm{~g}$ for 10 minutes, and the supernatant was removed. The pellet containing nanoparticles was rinsed with phosphate-buffered saline (PBS) twice to remove any remaining methanol and sodium hydroxide. PBS rinses were performed by adding $0.5 \mathrm{ml}$ of PBS to the nanoparticles and centrifuging at $8,960 \mathrm{~g}$ for 10 minutes. After the second rinse, the SFCS-coated curcumin nanoparticles were suspended in PBS for further analysis.

\section{Size measurement using transmission electron microscopy (TEM)}

SFCS-coated curcumin samples suspended in PBS were imaged using a JEM 1010 transmission electron microscope (TEM; JEOL USA Inc., Peabody, MA). Samples were placed on formver-coated and carbon-coated copper grids treated with poly-L-lysine for one hour. The samples were then blotted dry and imaged. The size of the nanoparticles from TEM images was measured using ImageJ software.

\section{Curcumin entrapment efficiency and release}

After collecting the nanoparticles from glass slides, the methanol/sodium hydroxide rinse and two subsequent PBS rinses (as defined above) were collected to calculate entrapment efficiency. The curcumin that was not entrapped (not coated with SFCS) was completely soluble in organic solvent and, hence, was collected in the methanol rinses. The amount of curcumin in the samples was measured by reading the absorbance at $424 \mathrm{~nm}$ using UV spectrophotometer (ThermoSpectronics, Rochester, NY) and calculated from the curcumin standard in ethanol. ${ }^{5}$ Similarly, for drug release, the nanoparticle suspension was centrifuged at $8,960 \mathrm{~g}$ for 10 minutes and absorbance was measured in the supernatant. The pellet was again suspended in PBS for the next time point and kept in a $37^{\circ} \mathrm{C}$ incubator shaker. 


\section{Cell culture}

Breast cancer cell lines MCF-7 (Her2-) and MDA-MB-453 (Her2+) were obtained from American Type Culture Collection (ATCC, Manassas, VA). MCF-7 cells were cultured in Dulbecco Modified Eagle's Medium with F-12 (Invitrogen, Grand Island, NY) and MDA-MB-453 cells in Leibovitz's L-15 medium (ATCC). Both culture mediums were supplemented with $10 \%$ fetal bovine serum (Atlanta Biologicals, Lawrenceville, GA) and 1\% antibiotic solution (Invitrogen).

\section{Assay for intracellular uptake of curcumin} MCF-7 and MDA-MB-453 cells were seeded in 96-well plates $(2,000$ cells/well) and incubated overnight. SFCS- or SF-coated nanocurcumin was added to each well at a concentration of $83.3 \mu \mathrm{g}$ curcumin/well and incubated for four days. The nanoparticles contained in the medium were removed from the wells. Cells were lysed in $100 \mu \mathrm{l}$ of dimethyl sulfoxide (DMSO; Fisher Scientific, Pittsburg, PA). A $50 \mu 1$ cell lysis suspension was reserved for absorbance measurement and the other $50 \mu \mathrm{l}$ for fluorescence measurements using a VersaFluor fluorometer (Bio-Rad Laboratories, Hercules, CA). Two filters were utilized with $480 \mathrm{~nm}$ excitation and $520 \mathrm{~nm}$ emission wavelengths. Since curcumin has auto-fluorescence properties, ${ }^{9}$ fluorescence assays were used in conjunction with absorbance to confirm the curcumin uptake measurements.

\section{Cell viability assay}

To measure the efficacy of nanocurcumin on MCF-7 and MDA-MB-453, the cells were seeded in 96-well plates (2,000 cells/well) and incubated overnight. Nanocurcumin coated with SFCS or SF was added to each well at a concentration of $83.3 \mu \mathrm{g}$ curcumin/well and incubated for four days. The nanoparticles contained in the medium were removed from the wells and a CellQuanti-MTT cell viability assay kit (BioAssay Systems, Hayward, CA) was used to determine the viability of cells remaining in each well. Briefly, $80 \mu \mathrm{l}$ of culture medium and $15 \mu \mathrm{l}$ of MTT reagent were added to each well and incubated for four hours. Then, MTT solubilization solution $(100 \mu \mathrm{l})$ was added to each well, and the plates were placed on a shaker for one hour. The absorbance readings were taken at $570 \mathrm{~nm}$ using a MRX Microplate Reader (Dynex Technologies, Guernsey, Channel Islands, UK).

\section{Statistical analysis}

All data analysis was performed using SigmaStat statistical program. One-way analysis of variance (ANOVA) was used with post-hoc Tukey test for pair-wise comparisons. All data was represented as mean \pm standard error of mean (SEM) and level of significance was chosen as $p<0.05$.

\section{Results}

\section{Nanoparticle size measurement}

SF- or SFCS-encapsulated curcumin nanoparticles fabricated with either $0.1 \% \mathrm{w} / \mathrm{v}$ or $10 \% \mathrm{w} / \mathrm{v}$ SF or SFCS were imaged using TEM to characterize the size (Figure 1). Size measurements of curcumin encapsulated particles showed that all formulations resulted in particles of sizes less than $100 \mathrm{~nm}$ except for $0.1 \% \mathrm{w} / \mathrm{v}$ 50:50 SFCS $(130 \pm 4.2 \mathrm{~nm})$ (Figure 2). Particle size of curcumin coated with $0.1 \%$ $\mathrm{w} / \mathrm{v}$ SF was significantly lower than $0.1 \% \mathrm{w} / \mathrm{v} 50: 50 \mathrm{SFCS}$ $(\mathrm{p}<0.001)$ and higher than $0.1 \% \mathrm{w} / \mathrm{v} 25: 75 \mathrm{SFCS}$ and $0.1 \%$ $w / v 75: 25$ SFCS $(p<0.001)$ fabricated particles. The particle size for 10\% w/v 75:25 SFCS was significantly higher than $10 \% \mathrm{w} / \mathrm{v}$ SF, $10 \% \mathrm{w} / \mathrm{v} 25: 75 \mathrm{SFCS}$, and 10\% w/v 50:50 SFCS $(\mathrm{p}<0.001)$.

Although there are differences in the size of the nanoparticles between high and low concentrations of SF content, no specific trend was noted. The size of particles coated with $0.1 \% \mathrm{w} / \mathrm{v}$ SF and $0.1 \% \mathrm{w} / \mathrm{v} 50: 50 \mathrm{SFCS}$ was significantly higher than $10 \% \mathrm{w} / \mathrm{v}$ SF and $10 \% \mathrm{w} / \mathrm{v} 50: 50$ SFCS $(p<0.001)$. However, 0.1\% w/v 25:75 SFCS-coated nanoparticles were smaller than $10 \% \mathrm{w} / \mathrm{v} 25: 75$ SFCS-coated particles $(\mathrm{p}<0.05)$. The size of SF and SFCS control particles (without drug) were also measured (data not shown) and found to be comparable with curcumin-loaded particles.

\section{Curcumin entrapment efficiency}

The entrapment of curcumin was more than $96 \%$ for SF-coated nanoparticles for both $0.1 \%$ and $10 \% \mathrm{SF}$. The entrapment efficacy decreased to $64 \%-73 \%$ for SFCS coated nanoparticles regardless of concentration of SF and CS (Figure 3). Curcumin entrapment was significantly higher for $0.1 \% \mathrm{w} / \mathrm{v}$ SF $(\mathrm{p}<0.01)$ and $10 \% \mathrm{w} / \mathrm{v}$ SF $(\mathrm{p}<0.05)$ compared to all SFCS blends.

\section{In vitro curcumin release from nanoparticles}

The curcumin release profiles for both $0.1 \% \mathrm{w} / \mathrm{v}$ and $10 \%$ $\mathrm{w} / \mathrm{v}$ preparations showed an initial burst release (up to two days) of curcumin from both SF and SFCS blends (Figure 4). However, curcumin release from SFCS blends did not increase any further over eight days. The high and low concentrations of SF-coated curcumin nanoparticles consistently released curcumin in large amounts over eight 

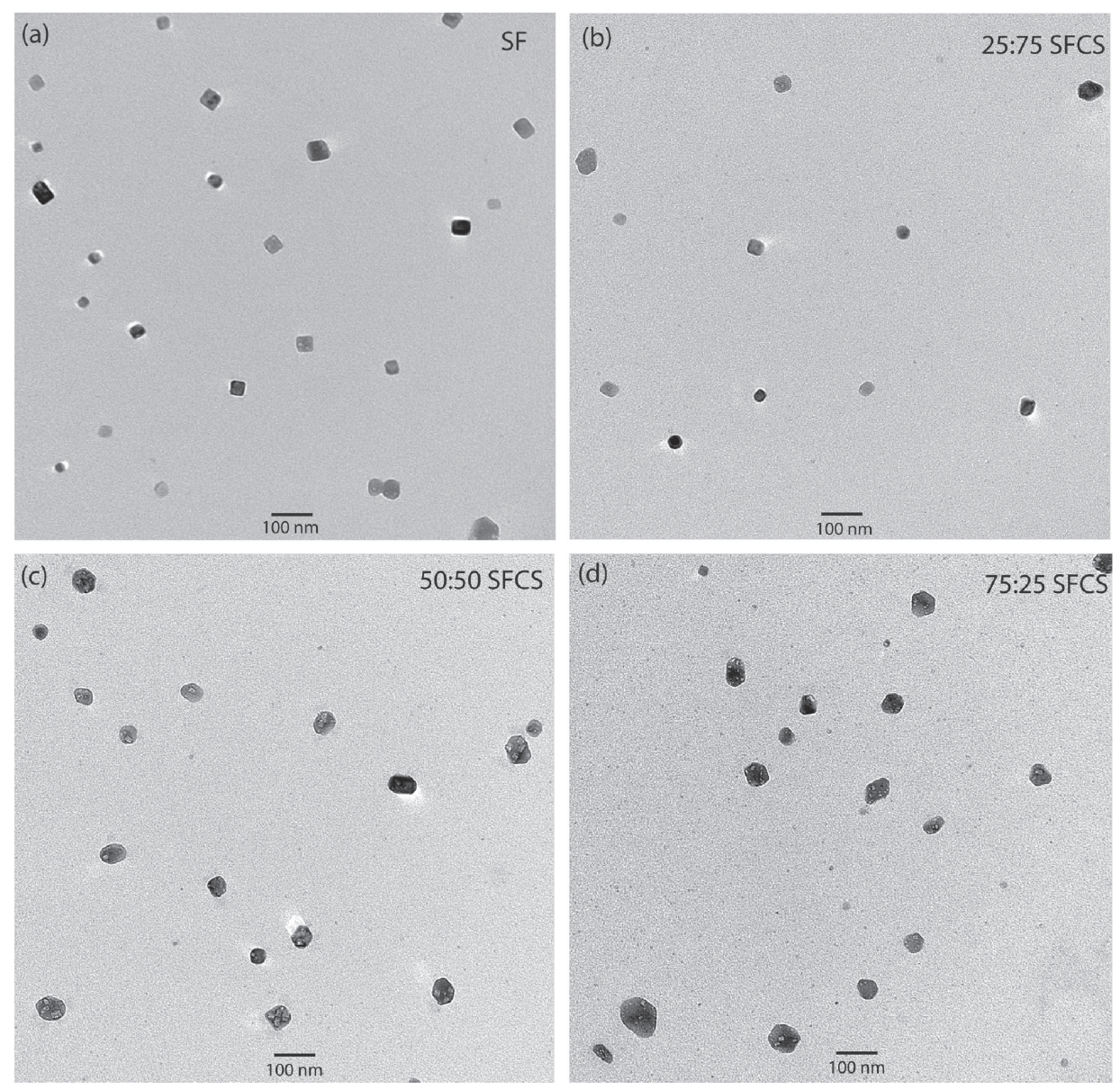

Figure I TEM images of the curcumin nanoparticle formulations. All blends of SFCS and SF alone were made of $10 \% \mathrm{w} / \mathrm{v}$ solution in these TEM images. Abbreviations: SF, silk fibroin; SFCS, silk fibroin and chitosan;TEM, transmission electron microscopy.

days. As shown in Figure 4, cumulative release of curcumin from SF-coated nanoparticles at day 8 was significantly higher than all other SFCS-blend nanoparticles $(\mathrm{p}<0.05$ for $0.1 \% \mathrm{w} / \mathrm{v}$ and $\mathrm{p}<0.001$ for $10 \% \mathrm{w} / \mathrm{v}$ solutions). Also, at day 8 the release from $10 \% \mathrm{SF}$ was significantly greater than $0.1 \% \mathrm{w} / \mathrm{v}$ SF $(\mathrm{p}<0.001)$.

The release of drugs from polymers has been previously modeled by the power law equation. ${ }^{17}$

$$
\frac{M_{t}}{M_{\infty}}=k t^{n}
$$

The ratio of $M_{t}$ and $M_{\infty}$, the amounts of drug at any time $t$ and at infinite time, respectively, was plotted against time, $t$, resulting in the derivation of parameters $k$ and $n$, which are dependent upon the composition/structure of the coating and release mechanism, respectively. Table 1 shows the values of $n$ and $k$ for all the nanoparticle formulations. The parameter $n$ ranged from 0.15 to 0.55 for the various nanoparticle formulations in Table 1, suggesting a diffusion-based release mechanism of curcumin from the nanoparticles. ${ }^{17}$ Based on $k$ values, the amount of drug released was significantly higher for $10 \% \mathrm{w} / \mathrm{v}$ SF as compared to $0.1 \% \mathrm{w} / \mathrm{v} \mathrm{SF}$ and all other SFCS blends $(\mathrm{p}<0.001)$.

\section{Intracellular uptake of curcumin}

The absorbance measurements of intracellular uptake of curcumin by Her2/neu low- and high-expressing breast cancer cells show that the curcumin uptake was highest from SF-coated nanoparticles as compared to the respective $0.1 \% \mathrm{w} / \mathrm{v}$ and $10 \% \mathrm{w} / \mathrm{v}$ SFCS blend groups (Figure 5). These differences were similar for both MCF-7 and MDA-MB-453 cells. The fluorescence measurements also showed similar uptake data as compared to the absorbance measurements (Figure 6). Interestingly, curcumin uptake by MDA-MB-453 cells was higher from $10 \% \mathrm{w} / \mathrm{v}$ SF-coated nanoparticles than $0.1 \% \mathrm{w} / \mathrm{v}$ SF-coated nanoparticles as measured by both absorbance and fluorescence. 


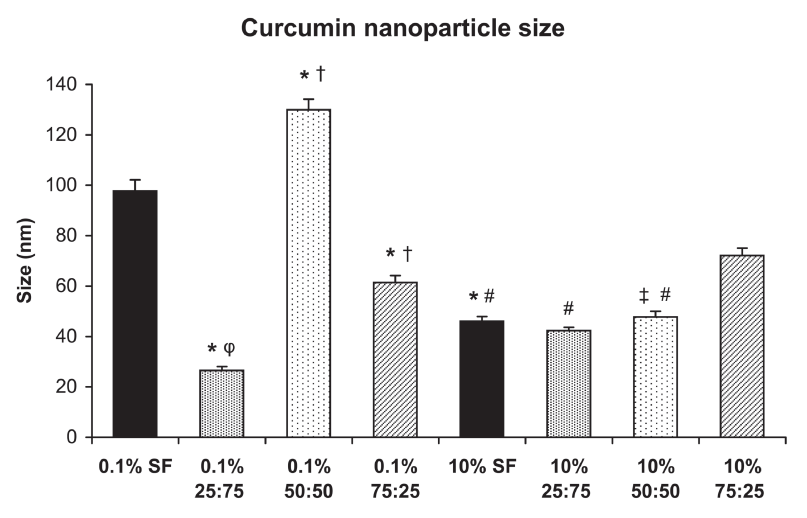

Figure 2 Curcumin nanoparticle sizes as measured from TEM images. Between 22 to 50 nanoparticles were measured from TEM images for each formulation. ${ }^{*} p<0.00$ I vs $0.1 \%$ SF, ${ }^{\dagger} \mathrm{p}<0.001$ vs $0.1 \% 25: 75$ SFCS, ${ }^{\phi} \mathrm{p}<0.05$ vs $10 \% 25: 75$ SFCS, ${ }^{\ddagger} \mathrm{p}<0.001$ vs $0.1 \%$ 50:50 SFCS, ${ }^{\#} \mathrm{p}<0.001$ vs 10\% 75:25 SFCS.

Abbreviations: SF, silk fibroin; SFCS, silk fibroin and chitosan; TEM, transmission electron microscopy.

\section{Curcumin nanoparticle efficacy against breast cancer cells}

The efficacy of curcumin nanoparticle formulations was measured for both MCF-7 and MDA-MB-453 cells using the MTT assay (Figure 7). The number of cells in the control samples (no nanoparticles) increased from 2,000 (initial density) to 3,563 \pm 215 (MCF-7) and $3,267 \pm 864$ (MDA-MB-453) over a period of four days. Exposure of $0.1 \% \mathrm{w} / \mathrm{v} \mathrm{SF}$ and $10 \% \mathrm{w} / \mathrm{v}$ SF nanocurcumin to MCF-7 and MDA-MB-453 cells significantly decreased the number of viable cells compared to controls $(\mathrm{p}<0.01)$. On the other hand, there was no difference in cell viability for the SFCS blends as compared to the control group. Also, the efficacy of $0.1 \% \mathrm{w} / \mathrm{v}$ SF was higher than $0.1 \% \mathrm{w} / \mathrm{v} 25: 75$ SFCS for MCF-7 cells $(\mathrm{p}<0.01)$ and $0.1 \% \mathrm{w} / \mathrm{v} 50: 50$ SFCS for MDA-MB-453 cells ( $p<0.01)$. Similarly, $10 \% \mathrm{w} / \mathrm{v}$ SF nanocurcumin had significantly higher efficacy against both

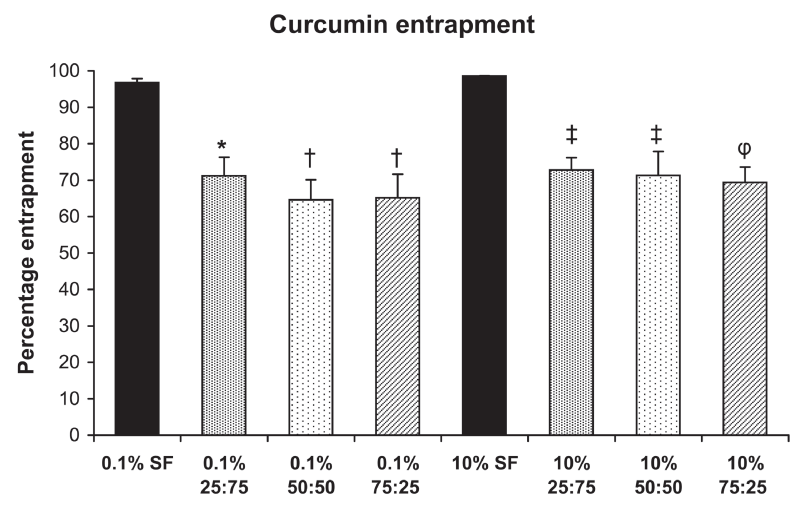

Figure 3 Curcumin entrapment within nanoparticles $(n=3)$. ${ }^{*} p<0.01$ vs $0.1 \% S F$, ${ }^{\dagger} \mathrm{p}<0.00$ I vs $0.1 \% \mathrm{SF},{ }^{\ddagger} \mathrm{p}<0.05$ vs $10 \% \mathrm{SF},{ }^{\dagger} \mathrm{p}<0.01$ vs $10 \% \mathrm{SF}$. Abbreviations: SF, silk fibroin.

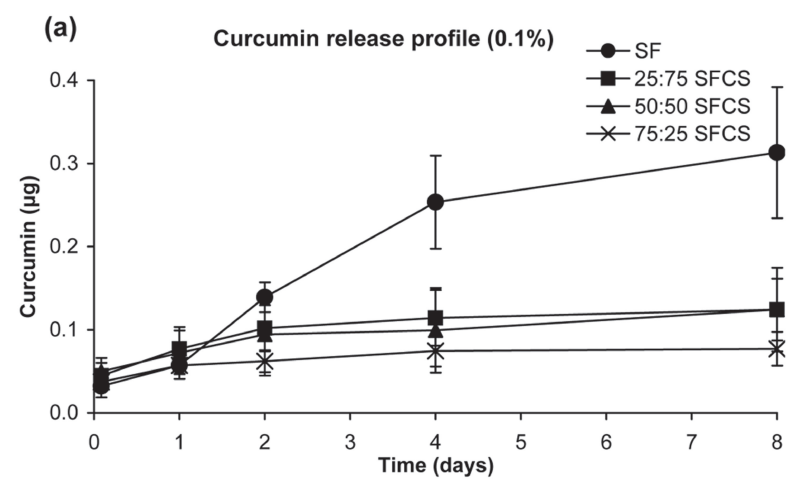

(b) Curcumin release profile (10\%)

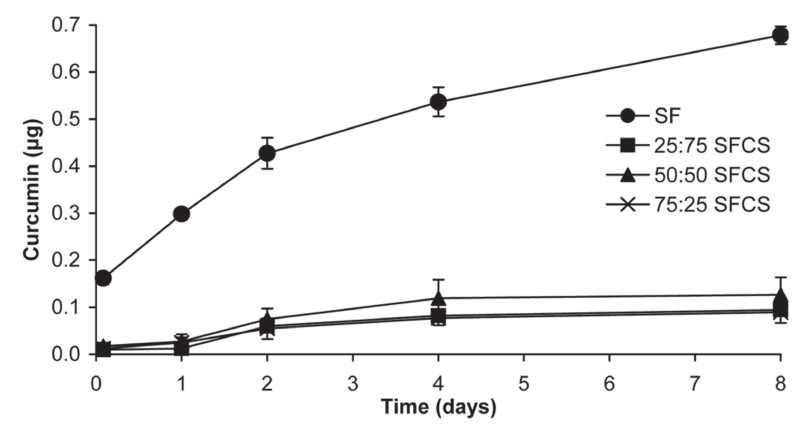

Figure 4 Cumulative curcumin release from nanoparticles over the period of eight days $(n=3)$. All blends of SFCS and SF alone were made of (a) $0.1 \%$ solution and (b) $10 \%$ solution.

Abbreviations: SF, silk fibroin; SFCS, silk fibroin and chitosan.

types of breast cancer cells as compared to $10 \% \mathrm{w} / \mathrm{v} 25: 75$ SFCS and 10\% w/v 50:50 SFCS $(\mathrm{p}<0.05)$.

\section{Discussion}

SF- and SFCS-coated curcumin nanoparticles $(<100 \mathrm{~nm})$ were fabricated and characterized. SF-coated nanoparticles showed the highest entrapment and release of curcumin, which resulted in higher intracellular uptake and efficacy

Table I The exponent ' $n$ ' and constant ' $\mathrm{k}$ ' values from the power law equation for various nanoparticle formulations.

\begin{tabular}{lll}
\hline Coatings & $\mathbf{n}$ & $\mathbf{k}\left(\times 10^{-4}\right.$ per/day $)$ \\
\hline $0.1 \%$ SF & $0.55 \pm 0.10$ & $0.9 \pm 0.1$ \\
$0.1 \% 25: 75 \mathrm{SFCS}$ & $0.25 \pm 0.05$ & $1.0 \pm 0.4$ \\
$0.1 \% 50: 50 \mathrm{SFCS}$ & $0.17 \pm 0.05$ & $1.0 \pm 0.5$ \\
$0.1 \% 75: 25 \mathrm{SFCS}$ & $0.15 \pm 0.05$ & $0.8 \pm 0.1$ \\
$10 \% \mathrm{SF}$ & $0.32 \pm 0.03$ & $3.0 \pm 0.0$ \\
$10 \% 25: 75 \mathrm{SFCS}$ & $0.28 \pm 0.18$ & $0.5 \pm 0.07$ \\
$10 \% 50: 50 \mathrm{SFCS}$ & $0.48 \pm 0.17$ & $0.6 \pm 0.06$ \\
$10 \% 75: 25 \mathrm{SFCS}$ & $0.45 \pm 0.08$ & $0.6 \pm 0.2$ \\
\hline
\end{tabular}

Abbreviations: SF, silk fibroin; SFCS, silk fibroin and chitosan. 
a) Curcumin uptake by MCF-7cells (Absorbance)

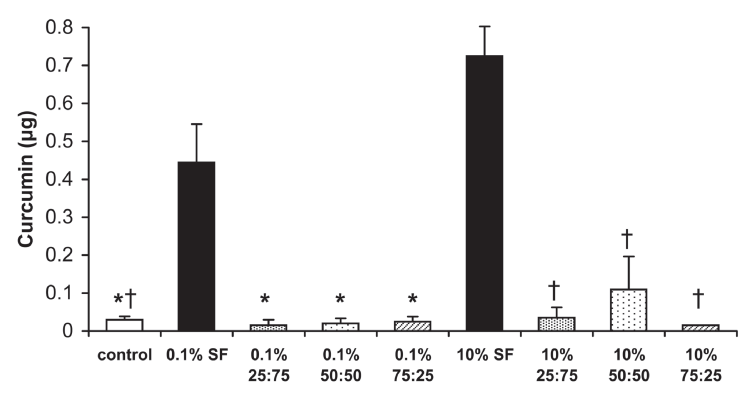

b) Curcumin uptake by MDA-MB-453 cells (Absorbance)

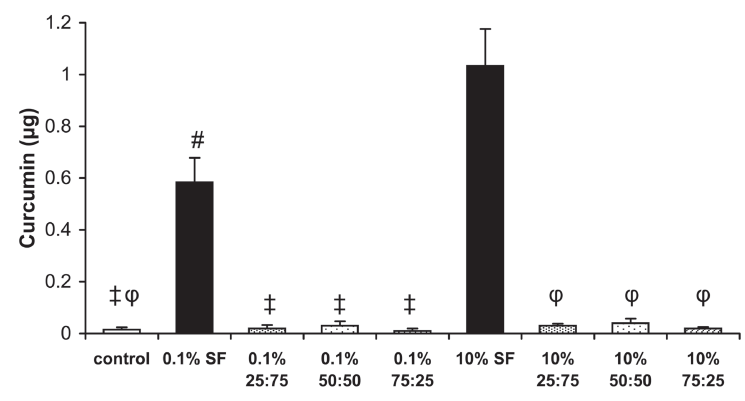

Figure $\mathbf{5}$ Intracellular uptake of curcumin by breast cancer cells as measured by absorbance assay after exposure to curcumin nanoparticles for four days $(n=3)$. (a) MCF-7, ${ }^{*} \mathrm{p}<0.01$ vs $0.1 \% \mathrm{SF},{ }^{\dagger} \mathrm{p}<0.001$ vs $10 \%$ SF (b) MDA-MB- $453,{ }^{\ddagger} \mathrm{p}<0.001$ vs $0.1 \% \mathrm{SF},{ }^{\circ} \mathrm{P}<0.00 \mathrm{I}$ vs $10 \% \mathrm{SF},{ }^{\#} \mathrm{p}<0.01$ vs $10 \% \mathrm{SF}$.

Abbreviation: SF, silk fibroin.

towards breast cancer cells. To our knowledge, only two other studies reported the fabrication of curcumin nanoparticles of less than $100 \mathrm{~nm},{ }^{4,5}$ however neither was manufactured from biologically derived regenerative biomaterials such as SF and CS. ${ }^{15}$

Curcumin entrapment was higher in SF-coated nanoparticles compared to all other SFCS blend formulations. The introduction of CS in the nanoparticle formulation of SF resulted in an increase of its hydrophilic character since CS is a water-carrying glucosamine molecule. Curcumin is a hydrophobic drug and hence the presence of CS with SF may have resulted in reducing the entrapment efficiency of curcumin. A very small amount $(0.09-0.13 \mu \mathrm{g})$ of curcumin was released from the SFCS-coated nanoparticles as compared to SF-coated nanoparticles $(0.32-0.68 \mu \mathrm{g})$ over eight days, which may have resulted from lower initial entrapment. The curcumin entrapment was initially low in SFCS coated nanoparticles resulting in the overall reduced release. Due to lower entrapment, the diffusion gradient of curcumin release from SFCS nanoparticles was also less as compared to SF-encapsulated curcumin nanoparticles. Previously, drug release from SF-coated liposomes was also found to be diffusion-controlled. ${ }^{13}$

The intracellular uptake of curcumin was also highest for the SF-coated nanoparticles compared to SFCS blends, which

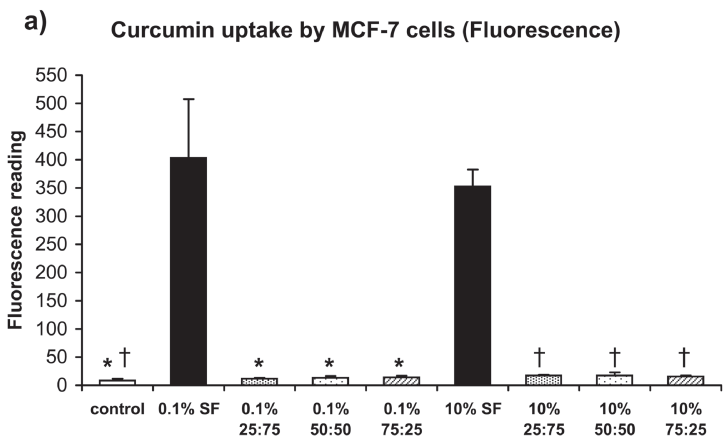

b) Curcumin uptake by MDA-MB-453 cells (Fluorescence)

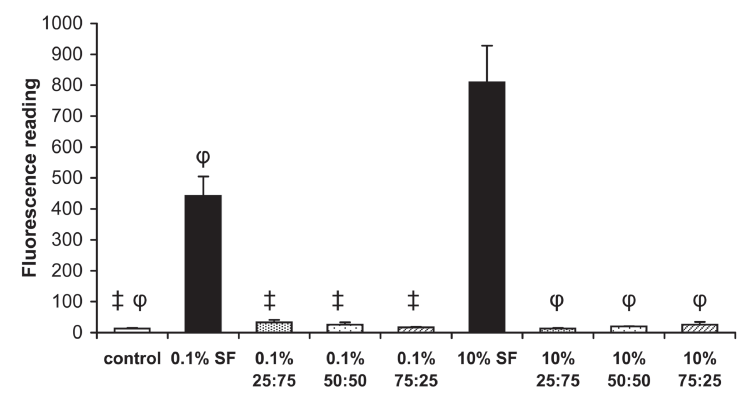

Figure $\mathbf{6}$ Intracellular uptake of curcumin by breast cancer cells as measured by fluorescence assay after exposure to curcumin nanoparticles for four days $(n=3)$. (a) MCF-7, ${ }^{*} \mathrm{p}<0.01$ vs $0.1 \% \mathrm{SF},{ }^{\dagger} \mathrm{p}<0.05$ vs $10 \% \mathrm{SF}$ (b) MDA-MB-453, ${ }^{\ddagger} \mathrm{p}<0.001$ vs $0.1 \% S F,{ }^{\phi} P<0.00 I$ vs $10 \% \mathrm{SF}$.

Abbreviation: SF, silk fibroin.

followed the curcumin entrapment and release data. Other than the nanoparticle size, the effect of concentration $(10 \% \mathrm{w} / \mathrm{v}$ vs $0.1 \% \mathrm{w} / \mathrm{v}$ ) was only evident in the intracellular uptake of curcumin by MDA-MD-453 cells. The curcumin uptake was significantly higher from $10 \% \mathrm{w} / \mathrm{v}$ SF than $0.1 \% \mathrm{w} / \mathrm{v}$ SF nanoparticles as measured by both absorbance and fluorescence assays. The effect of SF on the efficacy of breast cancer cells was previously studied with the SF coating of emodin-loaded liposomes. The SF coating of emodin-loaded liposomes was shown to have higher efficacy in Her2/neu high-expressing breast cancer cells (MDA-MB-453). ${ }^{14}$ Due to higher retention of emodin in the Her2/neu high expressing breast cancer cells, more signal transduction pathways were affected resulting in higher efficacy as compared to uncoated emodin-loaded liposomes. In this study, the higher SF content $(10 \% \mathrm{w} / \mathrm{v})$ resulted in higher uptake and intracellular residence time for curcumin, which also increased efficacy against breast cancer cells. While the SF coating of emodin in the study by Cheema and colleagues was $0.1 \% \mathrm{w} / \mathrm{v} \mathrm{SF},{ }^{14}$ we found that increasing the SF coating amount from $0.1 \% \mathrm{w} / \mathrm{v}$ to $10 \% \mathrm{w} / \mathrm{v}$ increased the curcumin entrapment and cellular uptake significantly, thereby affecting efficacy.

The efficacy of SF-coated nanocurcumin on breast cancer cells was significantly higher than SFCS-coated 

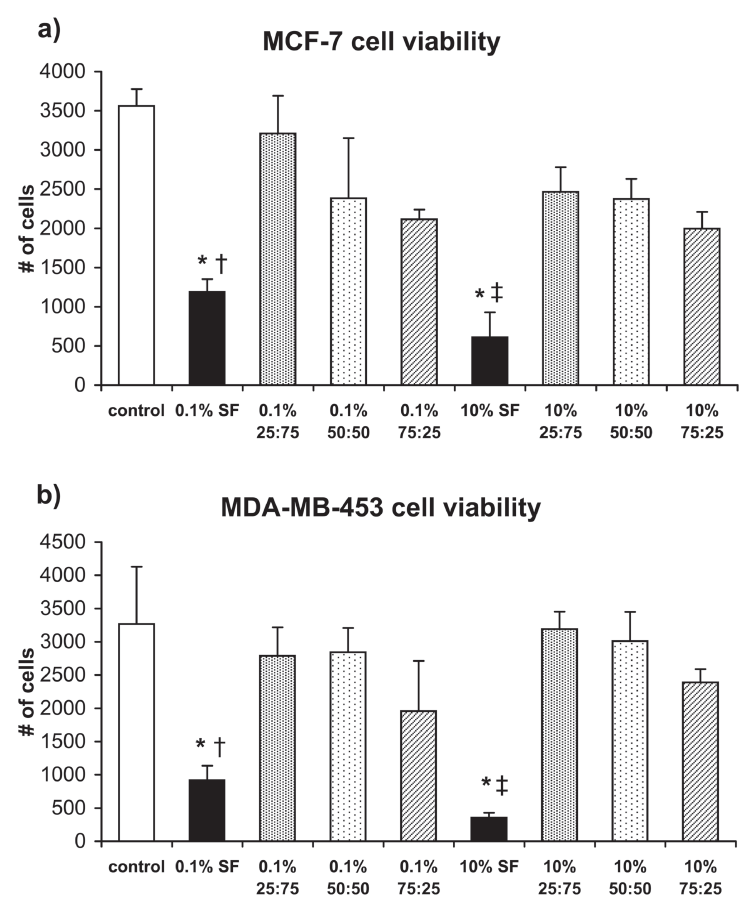

Figure 7 Cell viability measured by MTT assay after exposure to curcumin nanoparticles for four days $(n=3)$. (a) MCF-7, ${ }^{*} \mathrm{p}<0.001$ vs control, ${ }^{\dagger} \mathrm{p}<0.0 \mathrm{I}$ vs $0.1 \% 25: 75$ SFCS, ${ }^{\ddagger} \mathrm{p}<0.05$ vs $10 \% 25: 75$ SFCS and 10\% 50:50 SFCS (b) MDA-MB453 , ${ }^{*} \mathrm{p}<0.01$ vs control, ${ }^{\dagger} \mathrm{p}<0.01$ vs $0.1 \% 50: 50$ SFCS, ${ }^{\ddagger} \mathrm{p}<0.05$ vs $10 \% 25: 75$ SFCS and 10\% 50:50 SFCS.

Abbreviations: SF, silk fibroin; SFCS, silk fibroin and chitosan.

nanocurcumin. Efficacy data followed the curcumin uptake data, which showed high uptake of curcumin from SF-coated nanoparticles and hence reduced viability of Her2/neu high-expressing breast cancer cells. Previously, curcumin was shown to suppress Her2 and nuclear factor- $\kappa \beta$ pathways in breast cancer cells. ${ }^{3,18}$ Interestingly, Her2/neu low-expressing MCF-7 breast cancer cells also undergo apoptosis upon exposure to curcumin nanoparticles. Since curcumin is known to act through many pathways in various cancer cells, ${ }^{2}$ there may be a down modulation of more than one pathway in breast cancer cells due to longer availability of curcumin via SF nanoparticles. ${ }^{14}$

One of the limitations of this study was the minor drug loss during the transfer of nanoparticles from the glass slides. Although the use of the same procedure to transfer the nanoparticles should have minimized this effect when comparing groups. It was difficult to calculate the amounts of drug loss because entrapment efficiencies were calculated based on the un-entrapped drug during methanol/sodium hydroxide wash and the initial amount of drug used to mix with the SF or SFCS blends. However, it was evident from intracellular uptake and efficacy data that SF-coated nanoparticles entrapped and released the most drug as compared to other SFCS blend-coated nanoparticles. When considering the hydrophobic nature of curcumin with respect to the hydrophilic nature of chitosan, as mentioned earlier, this conclusion is logical. Another limitation of the study was the release of very small amounts of curcumin over time, which may be related to the medium (PBS) into which the release study was conducted. It is possible that the amount of released curcumin would be affected under serum or plasma conditions.

The treatment of several cancers in the future will be influenced by the ability of scientists to produce drug formulations that have high drug availability at tumor sites, sustained and long-term release, and minimal to no toxicity to healthy tissues. Biologically derived nanoparticles offer great promise in this regard due to the minimization of adverse effects while increasing the efficacy of the entrapped drug.

In conclusion, the SF- and SFCS-coated curcumin nanoparticles were fabricated using a novel technique. The size of the nanoparticles that showed high curcumin entrapment and efficacy towards breast cancer cells was less than $100 \mathrm{~nm}$. Nanoparticles of curcumin encapsulated with pure SF showed the highest curcumin entrapment, release, intracellular uptake, and efficacy towards breast cancer cells as compared to SFCS curcumin nanoparticles. The coating of SF can be used for nanoparticle preparation of numerous drugs or therapeutics for localized and long-term release for the treatment of cancer and many other diseases.

\section{Acknowledgments}

This research was funded by the Kyte Research Fund from the Department of Plastic Surgery at MD Anderson Cancer Center. We would also like to thank Kenneth Dunner Jr for processing the TEM samples at High Resolution Electron Microscopy Facility at MD Anderson Cancer Center.

\section{References}

1. Anand P, Kunnumakkara AB, Newman RA, Aggarwal BB. Bioavailability of curcumin: problems and promises. Mol Pharm. 2007;4(6):807-818.

2. Kunnumakkara AB, Anand P, Aggarwal BB. Curcumin inhibits proliferation, invasion, angiogenesis and metastasis of different cancers through interaction with multiple cell signaling proteins. Cancer Lett. 2008;269(2):199-225.

3. Hong RL, Spohn WH, Hung MC. Curcumin inhibits tyrosine kinase activity of p185neu and also depletes p185neu. Clin Cancer Res. 1999;5(7):1884-1891.

4. Sahu A, Bora U, Kasoju N, Goswami P. Synthesis of novel biodegradable and self-assembling methoxy poly(ethylene glycol)-palmitate nanocarrier for curcumin delivery to cancer cells. Acta Biomater. 2008;4(6):1752-1761

5. Bisht S, Feldmann G, Soni S, et al. Polymeric nanoparticle-encapsulated curcumin ("nanocurcumin"): a novel strategy for human cancer therapy. J Nanobiotechnology. 2007;5:3. 
6. Tiyaboonchai W, Tungpradit W, Plianbangchang P. Formulation and characterization of curcuminoids loaded solid lipid nanoparticles. Int J Pharm. 2007;337(1-2):299-306.

7. Sou K, Inenaga S, Takeoka S, Tsuchida E. Loading of curcumin into macrophages using lipid-based nanoparticles. Int J Pharm. 2008;352(1-2):287-293.

8. Li L, Braiteh FS, Kurzrock R. Liposome-encapsulated curcumin: in vitro and in vivo effects on proliferation, apoptosis, signaling, and angiogenesis. Cancer. 2005;104(6):1322-1331.

9. Kunwar A, Barik A, Pandey R, Priyadarsini KI. Transport of liposomal and albumin loaded curcumin to living cells: an absorption and fluorescence spectroscopic study. Biochim Biophys Acta. 2006;1760(10):1513-1520.

10. Wang X, Wenk E, Matsumoto A, Meinel L, Li C, Kaplan DL. Silk microspheres for encapsulation and controlled release. J Control Release. 2007;117(3):360-370.

11. Wenk E, Wandrey AJ, Merkle HP, Meinel L. Silk fibroin spheres as a platform for controlled drug delivery. J Control Release. 2008;132(1):26-34.

12. Wang X, Hu X, Daley A, Rabotyagova O, Cebe P, Kaplan DL. Nanolayer biomaterial coatings of silk fibroin for controlled release. J Control Release. 2007;121(3):190-199.
13. Gobin AS, Rhea R, Newman RA, Mathur AB. Silk-fibroin-coated liposomes for long-term and targeted drug delivery. Int J Nanomedicine. 2006;1(1):81-87.

14. Cheema SK, Gobin AS, Rhea R, Lopez-Berestein G, Newman RA, Mathur AB. Silk fibroin mediated delivery of liposomal emodin to breast cancer cells. Int J Pharm. 2007;341(1-2):221-229.

15. Gobin AS, Butler CE, Mathur AB. Repair and regeneration of the abdominal wall musculofascial defect using silk fibroin-chitosan blend. Tissue Eng. 2006;12(12):3383-3394.

16. Gobin AS, Froude VE, Mathur AB. Structural and mechanical characteristics of silk fibroin and chitosan blend scaffolds for tissue regeneration. J Biomed Mater Res A. 2005;74(3):465-473.

17. Siepmann J, Peppas NA. Modeling of drug release from delivery systems based on hydroxypropyl methylcellulose (HPMC). Adv Drug Deliv Rev. 2001;48(2-3):139-157.

18. Aggarwal BB, Shishodia S, Takada Y, et al. Curcumin suppresses the paclitaxel-induced nuclear factor-kappaB pathway in breast cancer cells and inhibits lung metastasis of human breast cancer in nude mice. Clin Cancer Res. 2005;11(20):7490-7498.
International Journal of Nanomedicine

\section{Publish your work in this journal}

The International Journal of Nanomedicine is an international, peerreviewed journal focusing on the application of nanotechnology in diagnostics, therapeutics, and drug delivery systems throughout the biomedical field. This journal is indexed on PubMed Central, MedLine, CAS, SciSearch ${ }^{\circledR}$, Current Contents ${ }^{\circledR} /$ Clinical Medicine,

\section{Dovepress}

Journal Citation Reports/Science Edition, EMBase, Scopus and the Elsevier Bibliographic databases. The manuscript management system is completely online and includes a very quick and fair peer-review system, which is all easy to use. Visit http://www.dovepress.com/ testimonials.php to read real quotes from published authors. 